ББК: 67.402

\title{
НАЛОГОВОЕ РЕГУЛИРОВАНИЕ ТРАНСФЕРТНОГО ЦЕНООБРАЗОВАНИЯ ФИНАНСОВЫХ СДЕЛОК В РОССИИ. КЭШ ПУЛИНГ.
}

\author{
(c) 2020 Тамбиев Руслан Магометович \\ аспирант \\ Российская академия народного хозяйства и государственной службы \\ при Президенте Российской Федерации, Россия, Москва \\ E-mail:r.m.tambiev@gmail.com
}

В статье описываются проблемы, возникающие при применении налоговых правил трансфертного ценообразования к договорам кэш пулинга. В частности, сложности возникают при определении «рыночного» вознаграждения участников договора кэш пулинга ввиду того, что заключение аналогичных договоров не характерно для независимых сторон вследствие чего, отсутствуют сопоставимые данные для определения «рыночных условий».

Цель исследования - предложения подхода к определению «рыночного вознаграждения» участников договора кэш пулинга для целей налогообложения. В статье анализируются положения публикаций Организации Экономического Сотрудничества и Развития (ОЭСР), законодательство Российской Федерации о налогах и сборах, а также судебная и административная практика по указанной проблеме.

Научная новизна заключается в предложении нового подхода к применению правил налогового контроля трансфертного ценообразования к договорам кэш пулинга. В частности, если результаты проведения функционального анализа, указывают на то, что кэш пул лидер осуществляет «рутинные функции», автор считает возможным установить в законе положения, которые позволяют без проведения рыночного исследования, устанавливать вознаграждение для целей расчета налоговой базы в размере 5-ти процентной надбавки к сумме расходов понесенных в рамках оказания указанной услуги. Если же кэш пул лидер выполняет и другие функции, то не исключено и более высокое вознаграждение, которое, например, может включать в себя доходную часть или весь спред между заемными и кредитными позициями кэш пул лидера.

Что касается вознаграждения участников кэш пулинга, то оно будет рассчитываться после расчета вознаграждения кэш пул лидера, на основе определения процентных ставок, применимых к дебетовой и кредитной позициям в рамках кэш пула.

Ключевые слова: Налоги, российское налоговое право, международное налоговое право, Организации экономического сотрудничества и развития, трансфертное ценообразование, принцип «вытянутой руки», взаимозависимые лица, кэш пулинг, функции казначейства, внутригрупповые услуги, внутригрупповые займы.

\section{Введение}

Актуальность. Использование механизма кэш пулинга пользуется популярностью среди транснациональных корпораций (далее - ТНК) в качестве способа обеспечения более эффективного управления денежными потоками [1, c. 44] за счет объединения на основном банковском счете (т.н. «мастер-счет»), физически и (или) условно [2, абз. 5268], остатков средств на банковских счетах компаний группы, которые будут находиться под управлением единого казначейского центра [3, с. 977] - кэш пул лидера (компании, которая осуществляет казначейские функции в рамках договора кэш пулинга).

Договоры о кэш пулинге представляют собой сложные договоры, которые могут предусматривать осуществление контролируемых и неконтролируемых операций для целей налогообложения [4, абз. 44]. Иными словами, договоры кэш пулинга, в зависимости от условий могут подпадать под налоговый контроль трансфертного ценообразования, в рамках которой они будут проверены на соблюдение «принципа вытянутой руки».

Цели и задачи исследования. Целью исследования является выявление существующих 
пробелов и неопределенностей в российском налоговом законодательстве в отношении налогообложения участников кэш пулинга и разработать предложения по их устранению.

Для достижения указанной цели были поставлены следующие задачи:

- Провести анализ публикаций Организации экономического сотрудничества и развития (ОЭСР) по указанному вопросу;

- Провести анализ российского налогового законодательства;

- Провести анализ российской судебной и административной практики.

Методологическую основу исследования составили как общенаучные методы познания (методы анализа, синтеза, индукции, дедукции и т.д.), так и специальные юридические методы (сравнительно-правовые, формальнодогматические и историко-правовые).

Степень разработанности темы и научная новизна. Несмотря на актуальность темы, она еще не нашла должного внимания в юридической науке. В научных трудах большое внимание уделяется общим правилам налогового контроля трансфертного ценообразования (наиболее актуальная работа была написана в 2017 году Задорожной А.И. [5]), но при этом не были обнаружены отечественные научные труды, связанные с налоговыми правилами трансфертного ценообразования для договоров кэш пулинга.

Теоретическая и практическая значимость. ОЭСР в своих публикациях отмечает, что практическая сложность применения принципа «вытянутой руки» заключается в том, что взаимозависимые лица могут участвовать в сделках, которые не характерны для независимых сторон, вследствие чего практически отсутствуют прямые доказательства того, какие условия были бы установлены независимыми организациями. Такие операции не обязательно могут быть мотивированы уклонением от уплаты налогов, но могут иметь место потому, что при осуществлении операций друг с другом, например ТНК сталкиваются с иными коммерческими обстоятельствами, по сравнению с независимыми компаниями [6, п. 1.11].

K этой категории операций относиться и кэш пулинг, поскольку операции по объединению денежных средств на едином банковском счете не проводятся на регулярной основе, а то и вовсе не осуществляются независимыми организациями. Это приводит к сложностям опреде- ления «рыночного» вознаграждения участников кэш пула для целей налогообложения, что в свою очередь указывает на целесообразность анализа указанного вопроса.

Применение правила трансфертного ценообразования к договорам кэш пулинга

Принцип «вытянутой руки» или «The Arm's Length Principle» является ключевым принципом налогового контроля трансфертного ценообразования во всем мире. Основная идея указанного принципа заключается в следующем: в ситуациях когда между двумя взаимозависимыми сторонами сделки в их коммерческих или финансовых отношениях устанавливаются условия, отличающиеся от тех, которые бы имели место в сделках между независимыми сторонами прибыль, которую должна была получить одна сторона такой сделки, но в силу указанных условий не была получена, должна быть включена в прибыль этой стороны и облагаться соответствующим налогом [6, п. 1.6].

Принцип «вытянутой руки» также нашел отражение в российском налоговом законодательстве (ст. 105.3 НК РФ). Данный концепт реализуется через огромное количество механизмов и инструментов, таких как законодательно установленных методик расчета «рыночных цен», требований по подготовке соответствующей документации, установление санкций за нарушение предписаний и т. д, то есть через т.н. правила налогового контроля трансфертного ценообразования. Правилам налогового контроля трансфертного ценообразования посвящен раздел V.1 НК РФ [7].

Субъектами правоотношений, возникающих при налоговом контроле трансфертного ценообразования, являются налоговые органы и т.н. взаимозависимые лица. Законодательное определение термина «взаимозависимые лиц» установлено в ст. 105.1. НК РФ. В более обобщенной формулировке «взаимозависимые лица» - это лица, особенности отношений между которыми могут оказывать влияние на условия и (или) результаты сделок, совершаемых этими лицами.

Правила налогового контроля трансфертного ценообразования применяется в ситуациях, когда условия, в которых совершаются сделки между взаимозависимыми лицами, отличаются от условий сделок, заключенных между независимыми сторонами, при этом сравниваются условия сопоставимых сделок (ст. 105.3 НК РФ). Правила определения сопоставимости указан- 
ных сделок также законодательно установлены (ст. 105.5 НК РФ).

Важно отметить, что в Российской Федерации налоговому контролю трансфертного ценообразования подлежат не все сделки между взаимозависимыми лицами, а только сделки, которые признаются контролируемыми в соответствии с законодательством Российской Федерации о налогах и сборах. Так, по российскому налоговому законодательству контролируемыми сделками признаются сделки между взаимозависимыми лицами и приравненные к ним сделки. При этом законодатель установил условия, при которых такие сделки признаются контролируемыми (ст. 105.14).

Законодательство Российской Федерации о налогах и сборах не содержит специальных правил для определения «рыночного» вознаграждения участников кэш пулинга. На момент написания данной статьи, судебная и административная практика по данному вопросу также не сформировалась.

11 февраля 2020 года ОЭСР опубликовала документ «Руководство по трансфертному ценообразованию в отношении финансовых сделок. Всеобъемлющие рамочные механизмы плана BEPS: Задачи 4, 8-10» [8] (далее - «Руководство в отношении финансовых сделок») который представляет собой рекомендации по трансфертному ценообразованию для финансовых сделок, в том числе для операций по договорам кэш пулинга [9].

Авторы указанного документа отмечают, что при оценке вопросов трансфертного ценообразования, связанных с договором кэш пулинга, надлежащее вознаграждение кэш пул лидера и других участников кэш пулинга будет зависеть от существующих фактов и обстоятельств, выполняемых функций, используемых активов и рисков, принимаемых в целях реализации механизма кэш пулинга [10].

Как правило, кэш пул лидер выполняет не более чем координационные или агентские функции, при этом мастер-счет является централизованным пунктом для осуществления ряда бухгалтерских проводок в целях обеспечения соблюдения предварительно установленных целевых показателей остатков средств на счетах участников кэш пула. С учетом ограниченного участия кэш пул лидера, его вознаграждение как правило, должно быть столь же ограниченным и соразмерен выполнению «рутинных» функций
[8, п. 10.130].

Если результаты проведения функционального анализа, указывают на то, что кэш пул лидер не несет никаких рисков (риск ликвидности, кредитный риск и т.д.), не использует уникальные нематериальные активы в процессе реализации механизма кэш пулинга, а просто выполняет координационную функцию, по мнению автора, подобную услугу можно квалифицировать как услуги с низкой добавленной стоимостью (оригинальное название «low value-adding intra-group services»), которые описаны в разделе D главы VII, Руководства ОЭСР по ТЦО [6, п. 7.44]. Позиция ОЭСР, в отношении возможности применения к подобным услугам «рыночного» вознаграждения в размере $5 \%$ к сумме расходов, связанных с оказанием этих услуг, также представляется обоснованной. Также ОЭСР указывает, что в подобных ситуациях анализ «рыночности» 5\% надбавки не является необходимым [6, п. 7.61]. Автор согласен с целесообразностью подобного подхода, поскольку он позволит сократить административную нагрузку как для налогоплательщиков, так и для налоговых органов.

Если же кэш пул лидер выполняет и другие функции, то не исключено и более высокое вознаграждение, которое может включать в себя доходную часть или весь спред между заемными и кредитными позициями компании. ОЭСР в своих публикациях отмечает, что итоговое вознаграждение кэш пул лидера может формироваться как его затраты увеличенные на сумму вознаграждения [8, п. 10.141].

Что касается вознаграждения участников кэш пулинга, то оно, как правило, будет рассчитываться, после расчета вознаграждения кэш пул лидера [8, п. 10.143]. При этом, как указывалось ранее, определение «рыночных» процентных ставок на сопоставимых условиях для внутригрупповых займов в рамках кэш пулинга может быть сопряжено с трудностями из-за отсутствия сопоставимых договоренностей между несвязанными сторонами. ОЭСР в своих публикациях отмечает, что в подобных ситуациях банковские договоренности с кэш пул лидером, учитывающие функциональные различия между банком и кэш пул лидером, а также варианты, реально доступные членам кэш пула, могут служить основой для определения сопоставимых процентных ставок при анализе трансфертного ценообразования [8, п. 10.145]. В процессе анализа также необходимо учитывать кредитные рей- 
тинги участников кэш пула и наличие гарантий по займам.

Следующее на что стоит обратить внимание, это наличие положительного эффекта для членов группы. Ожидается, что положение всех участников кэш пула будет лучше, чем при отсутствии механизма денежного пула. Например, в силу сложившихся фактов и обстоятельств всем участникам кэш пула может быть выгодно устанавливать более высокие процентные ставки, определяющие дебетовое и кредитное положение в рамках механизма кэш пулинга, по сравнению со ставками, которые они ожидают получить за счет заимствования или внесения наличных средств вне рамок пула. При этом, участники кэш пула могут быть готовы участвовать в механизмах кэш пула с целью получить доступ к иным преимуществам, помимо повышения процентных ставок, например, доступ к постоянному источнику финансирования, снижение зависимости от внешних банков или доступ к ликвидности, которого иначе они бы не получили [8, п. 10.146].

По российскому налоговому законодательству, по контролируемым займам налогоплательщик вправе признавать процентные доходы и расходы для целей налогообложения при условии, что ставка, по которой они были начислены находятся в интервале предельных значений установленных в ст. 269 НК РФ [11]. Например, по долговому обязательству, оформленному в евро, налогоплательщик вправе:

- признать доходом процент, исчисленный исходя из фактической ставки по таким долговым обязательствам, если эта ставка превышает 4 процентных пункта от Европейской межбанковской ставки предложения (EURIBOR);

- признать расходом процент, исчисленный исходя из фактической ставки по таким долговым обязательствам, если эта ставка меньше 7 процентных пунктов от Европейской межбанковской ставки предложения (EURIBOR)

Если фактические процентные ставки не находятся в интервалах установленных в ст. 269 НК РФ, то положения данной статьи указывают возможность применения общих правил трансфер- ного ценообразования установленных в разделе V.1 НК РФ.

\section{Заключение}

В конечном счете размер вознаграждения членов кэш пула будет зависеть от конкретных фактов и обстоятельств, а также от функций, активов и рисков каждого из членов пула. В частности, если результаты проведения функционального анализа, указывают на то, что кэш пул лидер осуществляет «рутинные функции», автор считает возможным установить в законе положения, которые позволяют без проведения рыночного исследования, устанавливать вознаграждение для целей расчета налоговой базы в размере 5-ти процентной надбавки к сумме расходов понесенных в рамках оказания указанной услуги. Если же кэш пул лидер выполняет и другие функции, то не исключено и более высокое вознаграждение, которое, например, может включать в себя доходную часть или весь спред между заемными и кредитными позициями кэш пул лидера.

Что касается вознаграждения участников кэш пулинга, то оно будет рассчитываться после расчета вознаграждения кэш пул лидера, на основе определения процентных ставок, применимых к дебетовой и кредитной позициям в рамках кэш пула.

Несомненно, фискальные органы не поощряют действий налогоплательщиков, преследующих снижение налоговой нагрузки, даже если такие действия формально не противоречат нормативным требованиям [12, с. 99]. В связи с этим, важно учитывать, что применение налогоплательщиками указанного подхода до его имплементации в налоговое законодательство может быть оспорено налоговыми органами [13, абз. 28]. Несмотря на то, что данный подход сформулирован на основе рекомендаций ОЭСР, необходимо помнить, что они не имеют силу закона [14, абз. 3034], [15, абз. 135], а также не предписывают порядок определения вознаграждения каждого участника кэш пула в какой-либо конкретной ситуации, а устанавливают принципы, которыми следует руководствоваться при таком распределении.

\section{Библиографический список}

1. Сунгатуллина Л.Б., Салахова Ю.Р. Особенности управления денежными потоками организации // Бухгалтерский учет в бюджетных и некоммерческих организациях. 2018. N 16. С. 40-46. 
2. Приказ Росстата от 24.07.2019 N 421 «Об утверждении форм федерального статистического наблюдения для организации федерального статистического наблюдения за ценами и финансами» // СПС «КонсультантПлюс» (дата обращения: 05.05.2020).

3. Заем, кредит, факторинг, вклад и счет: постатейный комментарий к статьям 807-860.15 Гражданского кодекса Российской Федерации / В. В.Байбак, О. М.Иванов, А. Г. Карапетов и др.; отв. ред. А. Г. Карапетов. М.: М-Логос, 2019. 1282 с.

4. Семенов С. Внутригрупповое финансирование с использованием займов и механизма кеш-пулинга не является способом получения необоснованной налоговой выгоды // СПС «КонсультантПлюс» 2016 (дата обращения: 05.05.2020).

5. Институт налогового контроля трансфертного ценообразования в Российской Федерации: диссертация кандидата юридических наук: 12.00.04 / Задорожная Анастасия Игоревна; [Место защиты: С.-Петерб. гос. ун-т]. Санкт-Петербург, 2017.- 270 с.

6. OECD (2017), OECD Transfer Pricing Guidelines for Multinational Enterprises and Tax Administrations 2017, OECD Publishing, Paris. URL://http://dx.doi.org/10.1787/tpg-2017-en/ (дата обращения: 05.05.2020)

7. «Налоговый кодекс Российской Федерации (часть первая)» от 31.07.1998 N 146-Ф3 (ред. от 01.04.2020)// Собрание законодательства Российской Федерации. № 31. 03.08.1998. Ст. 3824.

8. ЭСР (2020), Руководство по трансфертному ценообразованию в отношении финансовых сделок: Всеобъемлющие рамочные механизмы плана BEPS: Задачи 4, 8-10, ОЭСР, Париж. URL: www.oecd.org/tax/beps/ transfer-pricing-guidance-on-financial-transactions-inclusive-framework-on-beps-actions-4-8-10.htm (дата обращения: 05.05.2020).

9. ОЭСР опубликовала финальную версию Рекомендаций по трансфертному ценообразованию для финансовых сделок. URL: https://www.ey.com/ru_ru/tax/tax-alert/2020/03/ey-oesr-opublikovala-finalnuyu-versiyurekomendacij-po-transfertnomu-cenoobrazovaniyu-finansovyh-sdelok-10-march-2020-tax-rus (дата обращения: 05.05.2020)

10. Обновленные Рекомендации ОЭСР в отношении финансовых сделок. Почему они важны и как использовать их на практике? Вебинар, 12 марта 2020 года. URL: https://www2.deloitte.com/ru/ru/pages/tax/ events/2020/12-03.html (дата обращения: 05.05.2020)

11. «Налоговый кодекс Российской Федерации (часть вторая)» от 05.08.2000 N 117-Ф3 (ред. от 01.04.2020) // Собрание законодательства Российской Федерации. 07.08.2000. № 32. Ст. 3340.

12. Тамбиев P. М. Правовые пределы налогового планирования: где заканчивается налоговая оптимизация и начинается уклонение от налогов // Вопросы российского и международного права. 2016. № 4. С. 97-104.

13. Стадник Т.В. Практика применения трансфертного ценообразования: реалии и перспективы // Бизнес, Менеджмент и Право. 2018. N 4. С. 55-59. // СПС «КонсультантПлюс» 2016 (дата обращения: 05.05.2020).

14. Винницкий Д. В. Международное налоговое право: проблемы теории и практики. М.: Статут, 2017.463 с. // СПС «КонсультантПлюс» (дата обращения: 05.05.2020).

15. Чочиев А. В. Метод распределения прибыли в трансфертном ценообразовании // Право и экономика. 2018. N 12. С. 69-74. // СПС «КонсультантПлюс» (дата обращения: 05.05.2020). 